\title{
General Health during pregnancy and the post-partum period in women
}

\author{
Gayatri Raina $^{1}$, Puja Thakur ${ }^{2}$ \\ ${ }^{1}$ Assistant Professor \\ ${ }^{2}$ Research Scholar \\ Department of Psychology, Himachal Pradesh University, Summer Hills, Shimla (H.P.) \\ E-mail - gayatri.raina3@gmail.com \\ Corresponding Author - Gayatri Raina
}

\begin{abstract}
The present study was planned and executed with the aim to investigate general health during pregnancy and postpartum period among women. The sample comprised of 80 women who were selected from Indira Gandhi State Hospital, Shimla, Himachal Pradesh, and were observed during first trimester and third trimester of pregnancy and one month postpartum. In order to study general health among women, General Health Questionnaire- 28 (GHQ- 28) was used. Three sub-scales of GHQ- 28: somatic symptoms, anxiety, and social dysfunction scores were taken to measure general health of the selected sample of women. One way repeated analysis of variance was carried out to investigate general health among these women for the three time periods, i.e., first trimester, third trimester of pregnancy and one month postdelivery. The results revealed that (i) Women experienced significantly more somatic symptoms during first trimester as compared to third trimester of pregnancy and postpartum period. (ii) Women experienced significantly higher level of anxiety during first trimester as compared to third trimester of pregnancy and postpartum period. (iii) Women were significantly more socially dysfunctional during postpartum period as compared to first and third trimester of pregnancy.
\end{abstract}

Keywords: Somatic symptoms, Anxiety, Social dysfunction, pregnancy, postpartum period.

(Paper received $-14^{\text {th }}$ August 2017 , Peer review completed $-8^{\text {th }}$ September 2017)

(Accepted $-20^{\text {th }}$ September 2017)

\section{INTRODUCTION}

Pregnancy and postpartum period leave their imprints on every sphere of the life of a woman. Changes especially across pregnancy and their frequencies and intensity levels are different. First and third trimester of pregnancy have a surprising element as compared to second trimester of pregnancy. Hormonal changes [1] during first trimester results into different somatic problems like nausea, vomiting [2], headache and sleep disturbances [3-5]. Along with these physical problems, other psychological problems also ooze out from these changes like anxiety [6-8] and social dysfunction [9]. In certain cases these problems remain consistent even after delivery as well [10]. Child birth, regaining the normal shape of the body, reverting old hormonal changes and accepting the new hormonal changes further, pave a way to these psychological problems post- delivery [11]. Therefore, this leads to a need to focus on changes that occur in general health of women during pregnancy and postpartum period.

Health is a state of complete physical, mental and social well-being and not merely an absence of disease or infirmity [12]. Hence, general health includes every aspect of life. It does not include the working of the organs in the body only, but relationships, lifestyle and emotions as well. General health of a woman gets fluctuated during pregnancy and postpartum period drastically which gets manifested in the form of 
somatic symptoms [13], anxiety [14] and social dysfunction [15-16]. Somatic Symptom Disorder is characterized by somatic symptoms that are either very distressing or result in significant disruption of functioning, as well as excessive and disproportionate thoughts, feelings and behaviors regarding those symptoms [17]. The prevalence of somatic symptom disorder among women during pregnancy [13] and postpartum period [16] has been reported by many studies. Somatic symptoms like nausea and vomiting (NVP) are prominent during pregnancy especially in the beginning of pregnancy, i.e., first trimester. Usually mild nausea and vomiting are resolved by the twentieth week of gestation and limited to the first trimester but a small percentage of women have a prolonged course with symptoms extending until delivery. Various metabolic and neuromuscular factors have been reported as the cause of NVP [18]. Hueston and Miller [19] found that women's physical functioning and role limitation due to physical problems and pain also decreased as pregnancy progressed. These researchers also reported decreased level of physical health during the first two trimesters, with relative flattening in the third trimester. Similarly, Haas, Meneses and McCormick [20] evidenced a decline in physical functioning and emotional health during pregnancy which eventually resulted in adverse birth outcomes. They reported that women's poor physical functioning drastically fell from prior to pregnancy to during the third trimester. Haas and others [21] further, explored changes in health status of women and found a substantial decline in physical functioning from prior to pregnancy to during third trimester and the status improved during postpartum period. Similar results have been highlighted by Emmanuel and Sun [22] who indicated a significant improvement in physical health, physical role, bodily pain, vitality, emotional role and mental health except social functioning and maternal stress from late pregnancy to 6 weeks following childbirth and again at 12 weeks post-delivery.

Anxiety can be defined as unpleasant emotional state or condition characterized by subjective feelings of tension, apprehension and worry or autonomic arousal of nervous system. Anxiety disorders are common during the perinatal period among women than in the general population [23]. As far anxiety during pregnancy is concerned studies have indicated [24] that women reported higher level of anxiety during first trimester than third trimester of pregnancy. Anxiety gets manifested in the form of sleep disturbances. Lee and others [18] evidenced that there was a significant change in sleep patterns during first trimester as compared to pre- pregnancy sleep pattern. The women reported a significant increase in total sleep time but less deep sleep and more awakening during sleep during early gestation period. Further, the results revealed that by the third month postpartum, there was improvement in sleep characteristics. However, sleep efficiency remained significantly lower than baseline pre-pregnancy values. The study also concluded that sleep disturbance was greatest during the first postpartum month, particularly for first-time mothers. Andersson and others [25] reported that anxiety disorders are more prevalent during pregnancy as compared to postpartum period. Researchers [26-27] also reported prevalence of anxiety among women during pregnancy ( 27 per cent) and postpartum period (17 per cent).

Social dysfunction is a phenomenon of de-socialization due to a negative or hostile environmental reaction, or a consequence of a non-effective psychological strategy adapted by the affected persons to deal with the not so favorable circumstances [28]. Social dysfunction is seen as an artefact, a consequence of environmental stigma phenomenon. Environmental stigmas may be external deformation or physical deformities; deviations from personal traits like single parenting, dropping out of school, low salary, unemployment, criminal background, teenage pregnancy, alcoholism; and tribal stigma (nationality, religion or ethnicity). Researchers have found that women with social dysfunction were found psychologically distressed during pregnancy [29]. Otchet, Carey and Adam [30] studied general health and psychological symptoms in pregnancy and puerperium. The result showed very poor level of functioning in the third trimester with regard to bodily pain, physical functioning, social functioning, vitality, functional limitation resulting from physical health problems. These social and functional limitations caused by emotional problems remained persistent during puerperium but at lower level than were reported during pregnancy. Moreover, the findings showed that these problems were at higher level across pregnancy than puerperium. The pregnant women reported higher level of distress when compared with the community samples. They concluded that pregnancy and puerperium were significantly associated with psychological and physiological changes. Boyce and others [31] found that there was a decline in functioning and well-being during the postpartum period. 
In present study an effort has been made to understand how general health fluctuates from pregnancy to postpartum period. The major objectives of the study were -

- To study and compare somatic symptoms during pregnancy (first and third trimester) and postpartum period

- To measure and compare anxiety during pregnancy (first and third trimester) and postpartum period

- To evaluate and compare social dysfunction during pregnancy (first and third trimester) and postpartum period

\section{METHODOLOGY}

\section{Sample}

Purposive sampling was done for collecting data for the present investigation. The present study consisted of 80 pregnant educated women from Shimla town, Himachal Pradesh. These women were Hindus which is the majority community of the state and predominantly lived in joint families. All the selected women had full family and social support and had congenial environment at home. Majority of the women were primaparous and had intended/planned pregnancy. Most of the women of present research work belonged to lower middle section of society and majority of the women of the present research work were in the age range of 21-30 years. A little more one fourth of the sample (22) of the women was working. All these working women had full professional support of their colleagues and had congenial environment at their respective places of job. Out of these, very few women had regular and permanent jobs. The participants were informed about the nature of the study and their consent was taken.

\section{Tools}

To assess general health among women, General Health Questionnaire (GHQ-28) [32] was used. The scale consists of 28 items. These items have been divided into four sub- scales: somatic symptoms (item no. 1-7), anxiety (item no. 8-14), social dysfunction (item no. 15-21) and severe depression (22-28). For the present investigation the first three sub- scales only, i.e., somatic symptoms, anxiety and social dysfunction have been used. The questionnaire was scored on Likert scoring procedure (1, 2, 3, and 4). The total score ranges from $28-84$. The higher the score the poorer will be the general health of the respondent.

\section{Procedure}

The selected sample of women was approached during their first month of first trimester of their pregnancies and was again contacted in their third trimester (in the beginning of $8^{\text {th }}$ month of pregnancy). They were approached again during their early postpartum period, i.e., 20- 30 days after delivery.

\section{RESULTS AND DISCUSSION}

\section{Somatic Symptoms}

One way repeated analysis of variance was carried out to find out significant between group difference for somatic symptoms during first and third trimester of pregnancy and postpartum period. The summary of one way repeated analysis of variance for the scores is reported in Table 1.

As is evident from Table1 there was significant difference in somatic symptoms $(F=24.98 ; \mathrm{p}<.01)$ among the three time periods, i.e., first trimester, third trimester and the postpartum period.

The Mean scores and the standard deviations on somatic symptoms for the three time periods are presented in Table 2 . The result clearly indicates that the first trimester had highest mean score on somatic symptoms $(M=15.79)$ followed by the postpartum period $(M=14.19)$ and the third trimester $(M=12.41)$ got the least mean score.

It can be inferred from the results that somatic or physical health among the selected sample of women has fluctuated drastically and significantly during pregnancy and the postpartum period. More precisely, the women experienced highest somatic problems during first trimester as compared to third trimester and the postpartum period. Comparing third trimester with the postpartum period, it has been seen that the 
physical health of the women was affected more in the postpartum period than the third trimester. Interestingly, the somatic symptoms stabilized significantly during the period of third trimester.

These findings are in congruence with the findings of a previous study [19]. They suggested that physical health problems are higher in first trimester and flatten in the third trimester. These findings of the present investigation were further supported by the findings of the study which suggested that women reported obstetric condition as a cause of their physical or somatic problems during pregnancy [4].

This decline may be due to hormonal, cardiorespiratory and musculoskeletal changes that occur during pregnancy [2]. Further, the same findings were reported by Santos [5] who reported that physical activity decreased, especially from the first to the second trimester and to third trimester, in light and moderate intensity. Sukhee and Youngblut [10] observed in their study that caring for the newborn is related to higher level of maternal fatigue. Researchers [33] have also suggested that somatic symptoms were independently associated to day to day functioning of women after delivery.

Table 1: The Summary of One Way Repeated ANOVA for the Somatic Symptoms during the Three Time Periods, i.e., First Trimester, Third Trimester and Postpartum Period

\begin{tabular}{|c|c|c|c|c|}
\hline Source of Variation & Sum of Square & Df & Ms & $\mathrm{F}$ \\
\hline Between ss & 1560.97 & 79 & & \multirow{5}{*}{$\begin{array}{l}24.98 \\
p=0.0001^{* *}\end{array}$} \\
\hline Within ss & 1898 & 160 & & \\
\hline Treatment ss & 456.03 & 2 & 228.02 & \\
\hline Error & 1441.97 & 158 & 9.13 & \\
\hline Total & 3459 & 239 & & \\
\hline
\end{tabular}

Table 2: Means and SD for Somatic Symptoms during the Three Time Periods, i.e., First Trimester, Third Trimester and the Postpartum Period

\begin{tabular}{|l|l|l|}
\hline Somatic Symptoms & Means & SD \\
\hline FIRST TRIMESTER & 15.79 & 3.74 \\
\hline THIRD TRIMESTER & 12.41 & 3.33 \\
\hline POSTPARTUM PERIOD & 14.19 & 3.59 \\
\hline
\end{tabular}

\section{Anxiety}

The summary of one way repeated analysis of variance for the scores is reported in Table 3.

Table 3: The Summary of One Way Repeated ANOVA for the Anxiety during the Three Time Periods, i.e., First Trimester, Third Trimester and Postpartum Period

\begin{tabular}{|l|l|l|l|l|}
\hline $\begin{array}{l}\text { Source } \\
\text { Variation }\end{array}$ & Sum of Square & Df & Ms & \multirow{2}{*}{} \\
\hline Between ss & 1132.93 & 79 & & \multirow{2}{*}{21.71} \\
\hline Within ss & 2352 & 160 & & $\mathrm{P}=0.0001^{*}$ \\
\hline Treatment ss & 507.11 & 2 & 253.55 & \\
\hline Error & 1844.89 & 158 & 11.68 & \\
\hline Total & 3484.93 & 239 & & \\
\hline
\end{tabular}

Table 3 clearly indicates that there was significant difference in anxiety $(F=21.17 ; \mathrm{p}<.01)$ among three time periods of first trimester, third trimester and the postpartum period. The Mean scores and the standard deviations on anxiety levels for the three time periods are presented in Table 4 . 
Table 4: Means and SD for Anxiety during the Three Time Periods, i.e., First Trimester, Third Trimester and Postpartum Period

\begin{tabular}{|c|c|c|}
\hline Anxiety & Means & SD \\
\hline FIRST TRIMESTER & 14.93 & 4.15 \\
\hline THIRD TRIMESTER & 13.91 & 3.48 \\
\hline POSTPARTUM PERIOD & 11.46 & 2.90 \\
\hline
\end{tabular}

It is evident from the results that the women experienced significantly different levels of sleep and anxiety problems during the three time periods i.e. first and third trimester, and the postpartum period. Further, it has been observed that during first trimester the women had highest level of anxiety than third trimester and the postpartum period. The women also experienced higher anxiety during the third trimester as compared to the postpartum period. The trend is quite evident that anxiety gradually decreased from first to third trimester and finally it was lowest during the postpartum period. In other words, the selected sample of women was significantly more anxious during the first trimester than the third trimester and the postpartum period.

Researchers $[8,34]$ in their respective studies observed that somatic symptoms were higher in the first trimester as compared to later stage of pregnancy which they argued might have further resulted into higher level of anxiety among women during first trimester of pregnancy. Research has also found an association of anxiety during early pregnancy with severity of nausea and vomiting among the pregnant women [35]. Roesch and others observed that shorter the gestational period higher was the anxiety among the pregnant women [4]. The findings are supported by the study that found a decreasing trend in anxiety among the women from early pregnancy to late pregnancy and subsequently to postpartum period [36].

\section{Social Dysfunction}

The summary of one way repeated analysis of variance for the scores on Social Dysfunction is reported in Table 5 .

Table 5: The Summary of One Way Repeated ANOVA for the Social Dysfunction during the Three Time Periods, i.e., First Trimester, Third Trimester and Postpartum Period

\begin{tabular}{|c|c|c|c|c|}
\hline $\begin{array}{ll}\text { Source } & \text { of } \\
\text { Variation } & \end{array}$ & Sum of Square & $\mathrm{df}$ & Ms & $\mathrm{F}$ \\
\hline Between ss & 1440933 & 79 & & \multirow{5}{*}{$\begin{array}{l}63.73 \\
P<0.0001^{*}\end{array}$} \\
\hline within ss & 3814 & 160 & & \\
\hline Treatment ss & 1703.00 & 2 & 851.50 & \\
\hline Error & 2110.99 & 158 & 13.36 & \\
\hline Total & 5254.93 & 239 & & \\
\hline
\end{tabular}

Table 6: Means and SD for Social Dysfunction during the Three Time Periods, i.e., First Trimester, Third Trimester and Postpartum Period

\begin{tabular}{|l|l|l|}
\hline Social Dysfunction & Means & SD \\
\hline FIRST TRIMESTER & 18.04 & 4.48 \\
\hline THIRD TRIMESTER & 16.74 & 4.37 \\
\hline POSTPARTUM PERIOD & 22.93 & 2.41 \\
\hline
\end{tabular}


It can be summarized that the women were highly socially inactive during the postpartum period as compared to the two time periods during pregnancy. Moreover, the women were more socially restrained during first trimester than the third trimester.

Health issues, baby care and breast feeding during postpartum period [37] may have increased the social dysfunction among these women. They seem to be too much engrossed in resolving the post- delivery issues rather than focusing on social interactions. Researchers [38] also explained that women's functional status significantly lowered due to physical health problem after childbirth.

Research has investigated general health status and prevalence of common physical health conditions of women after childbirth. The study reported that women experienced certain conditions such as fatigue/ physical exhaustion, sleep related problems, pain, sex related concerns, hemorrhoids or constipation, and breast problems during postpartum. These somatic problems seem to have adversely affected social functioning among women [9].

As is evident from the results, the women experienced more somatic symptoms during the first trimester of pregnancy. This combination may act as a triggering process for the women to be socially dysfunctional during the first trimester of pregnancy. The findings are supported by the stigma model [39].

\section{CONCLUSION}

It is evident from the results that women experienced higher level of somatic symptoms, anxiety during first trimester of pregnancy as compared to third trimester and postpartum period. On the other hand, women were highly socially dysfunctional during postpartum period as compared to pregnancy, i.e., first and third trimester of pregnancy. Further, the results highlighted that general health got stabilized during third trimester of pregnancy. The present study scrutinized the urgent need to explore the trend of general health of women during first and third trimester of pregnancy and postpartum period. The study is limited in its implication in term of its sample size. Future studies should increase the sample size and also include second trimester of pregnancy. Further, future researches should investigate the effect of pregnancy and postpartum period on general health of partners of women as well.

\section{REFERENCES}

1. Hueston WJ, Kasik-Miller S. Changes in functional health status during normal pregnancy. J Fam Practice 1998;47(3):209-13.

2. Biringer A. Common Physical Discomforts of Pregnancy. Can Fam Physician 1998;34:1965-68.

3. Fiorini GT. The Inflammatory Theory of Pregnancy. Can Fam Physician 1969;15(5):55-9.

4. Sydsjö G, Sydsjö A. Newly delivered women's evaluation of personal health status and attitudes towards sickness absence and social benefits. Acta Obstetr Gynecol Scand 2002;81(2):104-11.

5. Santos PC, Abreu S, Moreira C, Santos R, Ferreira M, Alves O, Moreira P, Mota J. Physical activity patterns during pregnancy in a sample of Portuguese women: a longitudinal prospective study. Iran Red Cresc Med J 2016;18(3):e22455.

6. Roesch SC, Schetter CD, Woo G, Hobel CJ. Modeling the types and timing of stress in pregnancy. Anxiety Stress Coping 2004;17(1):87-102.

7. Köken G, Yilmazer M, Cosar EN, Sahi` n FG, Cevri` oglu S, Geci ci Ö. Nausea and vomiting in early pregnancy: relationship with anxiety and depression. J Psychosom Obstetr Gynecol 2008;29(2):91-5.

8. Yonkers KA, Wisner KL, Stewart DE, Oberlander TF, Dell DL, Stotland N, Ramin S, Chaudron L, Lockwood C. The management of depression during pregnancy: a report from the American Psychiatric Association and the American College of Obstetricians and Gynecologists. Gen Hosp Psychiatry 2009;31(5):403-13.

9. Cheng YW, Chung JH, Kurbisch-Block I, Inturrisi M, Shafer S, Caughey AB. Gestational weight gain and gestational diabetes mellitus: perinatal outcomes. Obstetr Gynecol 2008;112(5):1015-22.

10. Ahn S, Youngblut JM. Predictors of women's postpartum health status in the first 3 months after childbirth. Asian Nurs Res 2007;1(2):136-46.

11. Evans J, Heron J, Patel RR, Wiles N. Depressive symptoms during pregnancy and low birth weight at term. Br J Psychiatry 2007;191(1):84-5.

12. World Health Organization. Mental Health: A State of Well- Being, Geneva, WHO ; 2012. 
13. Evans J, Heron J, Francomb H, Oke S, Golding J. Cohort study of depressed mood during pregnancy and after childbirth. BMJ 2001;323(7307):257-60.

14. Ross LE, McLean LM. Anxiety disorders during pregnancy and the postpartum period: A systematic review. J Clin Psychiatry 2006;67(8):1285-98.

15. Boyce PM, Condon JT, Ellwood DA. Pregnancy loss: a major life event affecting emotional health and wellbeing. Med J Austr 2002;176(6):250-1.

16. Brown S, Lumley J. Physical health problems after childbirth and maternal depression at six to seven months postpartum. BJOG 2000;107(10):1194-201.

17. American Psychiatric Association. Diagnostic and Statistical Manual for the Classification of Psychiatric Disorders. $5^{\text {th }}$ edition. American Psychiatric Association ; 2013.

18. Lee KA, Zaffke ME, McEnany G. Parity and sleep patterns during and after pregnancy. Obstetr Gynecol 2000;95(1):14-8.

19. Hueston WJ. Techniques for antepartum fetal surveillance. Amer Fam Physician 1991;44(3):893-904.

20. Haas JS, Meneses V, McCornick MC. Outcomes and Health Status of Socially Disadvantaged Women during Pregnancy. J Wom Health Gend Based Med 1999;8:547-53.

21. Haas JS, Jackson RA, Fuentes- Afflick E, Stewart AL, Dean ML, Brawarsky P, Escobar GJ. Changes in the health status of women during and after pregnancy. J Gen Intern Med 2005;20(1):45-51.

22. Emmanuel EN, Sun J. Health related quality of life across the perinatal period among Australian women. J Clin Nurs 2014;23(11-12):1611-9.

23. Grigoriadis S, VonderPorten EH, Mamisashvili L, Tomlinson G, Dennis CL, Koren G, Steiner M, Mousmanis $\mathrm{P}$, Cheung A, Radford K, Martinovic J. The impact of maternal depression during pregnancy on perinatal outcomes: a systematic review and meta-analysis. J Clin Psychiatry 2013;74(4):e321-41.

24. Teixeira C, Figueiredo B, Conde A, Pacheco A, Costa R. Anxiety and depression during pregnancy in women and men. J Affect Disord 2009;119(1):142-8.

25. Anderson JE, Ebrahim S, Floyd L, Atrash H. Prevalence of risk factors for adverse pregnancy outcomes during pregnancy and the preconception period-United States, 2002-2004. Maternal Child Health J 2006;10(1):101-6.

26. Mina S, Balhara YPS, Verma R, Mathur S. Anxiety and Depression amongst the Urban Females of Delhi in Ante-Partum and Post-Partum Period. Delhi Psychiatry Journal 2012;15:347-51.

27. Sutter-Dallay AL, Giaconne-Marcesche V, Glatigny-Dallay E, Verdoux H. Women with anxiety disorders during pregnancy are at increased risk of intense postnatal depressive symptoms: a prospective survey of the MATQUID cohort. Eur Psychiatry 2004;19(8):459-63.

28. Stanghellini G, Ballerini M. Dis-Sociality: The Phenomenological Approach to Social Dysfunction in Schizophrenia. World Psychiatry 2012;1(2):102-10.

29. Kaasen A, Helbig A, Malt UF, Naes T, Skari H, Haugen G. Acute maternal social dysfunction, health perception and psychological distress after ultrasonographic detection of a fetal structural anomaly. BJOG 2010;117(9):1127-38.

30. Otchet F, Carey MS, Adam L. General health and psychological symptom status in pregnancy and the puerperium: what is normal?. Obstetr Gynecol 1999;94(6):935-41.

31. Johnstone SJ, Boyce PM, Hickey AR, Morris-Yates AD, Harris MG. Obstetric risk factors for postnatal depression in urban and rural community samples. Austr NZ J Psychiatry 2001;35(1):69-74.

32. Goldberg DP, Hillier VF. A scaled version of the General Health Questionnaire. Psychol Med 1979;9(1):13945.

33. Senturk V, Hanlon C, Medhin G, Dewey M, Araya M, Alem A, Prince M, Stewart R. Impact Of Perinatal Somatic And Common Mental Disorder Symptoms On Functioning In Ethiopian Women: The P-Mamie Population-Based Cohort Study. J Affect Disord 2012;136(3):340-9.

34. Chan SS, Cheung RY, Yiu KW, Lee LL, Chung TK. Prevalence of urinary and fecal incontinence in Chinese women during and after their first pregnancy. Int Urogynecol J 2013;24(9):1473-9.

35. Guler O, Koken GN, Emul M, Ozbulut O, Gecici O, Uguz F, Gezginc K, Zeytinci IE, Karatayli S, Askin R. Course of panic disorder during the early postpartum period: a prospective analysis. Compr Psychiatry 2008;49(1):30-4.

36. Heron J, O'Connor TG, Evans J, Golding J, Glover V, ALSPAC Study Team. The course of anxiety and depression through pregnancy and the postpartum in a community sample. J Affect Disord 2004;80(1):65-73.

37. Huizink AC, Mulder EJ, de Medina PG, Visser GH, Buitelaar JK. Is pregnancy anxiety a distinctive syndrome?. Early Hum Dev 2004;79(2):81-91.

38. Webb DA, Bloch JR, Coyne JC, Chung EK, Bennett IM, Culhane JF. Postpartum physical symptoms in new mothers: Their relationship to functional limitations and emotional well- being. Birth 2008;35(3):17987. 
39. Zubin J, Oppenheimer G, Neugebauer R. Degeneration theory and the stigma of schizophrenia. Biol Psychiatry 1985;20(11):1145-8.
$* * * * * * * * * * * * * * * * * * * * * *$
Acknowledgements - Nil
Source of Funding - Nil
Conflict of Interest - Nil 